\title{
Article \\ Association between Physical Activity and Sport Participation on Hemoglobin A1c among Children and Adolescents with Type 1 Diabetes
}

\author{
Kristi M. King ${ }^{1,2, *}$, Jason R. Jaggers ${ }^{1,2} \mathbb{1}$, Lindsay J. Della ${ }^{3}$, Timothy McKay ${ }^{1}$, Sara Watson ${ }^{1}$, Amy E. Kozerski ${ }^{4}$, \\ Kimberly R. Hartson ${ }^{5}$ and Kupper A. Wintergerst ${ }^{1}$ \\ 1 Wendy Novak Diabetes Center, Division of Pediatric Endocrinology, School of Medicine, \\ University of Louisville, Louisville, KY 40202, USA; Jason.Jaggers@louisville.edu (J.R.J.); \\ timothy.mckay@louisville.edu (T.M.); sara.watson@louisville.edu (S.W.); \\ kupper.wintergerst@louisville.edu (K.A.W.) \\ 2 Department of Health and Sport Sciences, University of Louisville, Louisville, KY 40292, USA \\ 3 Department of Communication, University of Louisville, Louisville, KY 40292, USA; \\ Lindsay.Della@louisville.edu \\ 4 Epidemiology and Cancer Control, St. Jude Children's Research Hospital, Memphis, TN 38105, USA; \\ amy.kozerski@stjude.org \\ 5 School of Nursing, University of Louisville, Louisville, KY 40292, USA; Kimberly.rapp@louisville.edu \\ * Correspondence: kristi.king@louisville.edu; Tel.: +1-502-852-8843
}

Citation: King, K.M.; Jaggers, J.R.; Della, L.J.; McKay, T.; Watson, S.; Kozerski, A.E.; Hartson, K.R.; Wintergerst, K.A. Association between Physical Activity and Sport Participation on Hemoglobin A1c among Children and Adolescents with Type 1 Diabetes. Int. J. Environ Res. Public Health 2021, 18, 7490 https://doi.org/10.3390/ ijerph18147490

Academic Editor: Laura L. Hayman

Received: 27 May 2021

Accepted: 9 July 2021

Published: 14 July 2021

Publisher's Note: MDPI stays neutral with regard to jurisdictional claims in published maps and institutional affiliations.

Copyright: (c) 2021 by the authors. Licensee MDPI, Basel, Switzerland. This article is an open access article distributed under the terms and conditions of the Creative Commons Attribution (CC BY) license (https:// creativecommons.org/licenses/by/ $4.0 /)$.
Abstract: Purpose: To determine associations between physical activity (PA) and sport participation on $\mathrm{HbA1c}$ levels in children with type 1 diabetes (T1D). Method: Pediatric patients with T1D were invited to complete a PA and sport participation survey. Data were linked to their medical records for demographic characteristics, diabetes treatment and monitoring plans, and $\mathrm{HbA} 1 \mathrm{c}$ levels. Results: Participants consisted of 71 females and 81 males, were $13 \pm 3$ years old with an average HbA1c level of $8.75 \pm 1.81$. Children accumulating $60 \mathrm{~min}$ of activity 3 days or more a week had significantly lower $\mathrm{HbA1c}$ compared to those who accumulated less than 3 days $(p<0.01)$ of 60 min of activity. However, there was no significant difference in $\mathrm{HbA} 1 \mathrm{c}$ values based on sport participation groups. A multiple linear regression model indicated that PA, race, age, duration of diagnosis, and CGM use all significantly predicted $\mathrm{HbA} 1 \mathrm{c}(p<0.05)$. Conclusion: This study demonstrated the significant relationship between daily $\mathrm{PA}$ and $\mathrm{HbA1c}$. Those in this sample presented with lower $\mathrm{HbA1c}$ values even if accumulating less than the recommended number of days of activity. Further, it was shown that sport participation alone may not be adequate enough to impact $\mathrm{HbA} 1 \mathrm{c}$ in a similar manner.

Keywords: physical activity; pediatric; clinical exercise; sport medicine; diabetes

\section{Introduction}

Children with type 1 diabetes (T1D) should engage in a minimum of 60 min of moderate to vigorous intensity physical activity (PA) per day, the same as children without T1D. However, due to the inability of the body's natural response to control glucose fluctuations, care must be taken to prevent incidents of low blood glucose levels (hypoglycemia) or high blood glucose levels (hyperglycemia) during and after physical activity [1-6]. A continuous, dynamic, and complex balance of insulin administration, nutrition, PA, and monitoring of blood glucose levels are required to manage T1D. Children with T1D can still maintain a healthy and physically active lifestyle through recreational and general play as well as by participating in sports and organized activities as long as necessary safety precautions are taken. Scientific guidance exists regarding glucose targets for safe and effective participation in PA as well as nutritional and insulin dose adjustments to protect against PA-related glucose excursions [7-9]. 
There have been a number of studies investigating the impacts of sedentary lifestyles compared to physically active lifestyles in patients with T1D outcomes [10-13], however the majority of studies were conducted with older populations and there is limited information in regards to PA and sports participation available for children with T1D. Participation in sports is an excellent way for children to accumulate PA, while also gaining valuable social and life skills. Furthermore, studies have shown that children who participate in sports were more likely to meet PA guidelines than children who do not participate in sports [14].

There is evidence to suggest that PA in youth with T1D can contribute to decreases in HbA1c [10-13]. For example, among children with T1D, less active children have been known to exhibit poor glycemic control and significantly higher $\mathrm{HbA1c}$ levels compared to children who accumulate more physical activity most, if not all, days of the week $[15,16]$. Although sport participation can be a way for T1D patients to be physically active and perhaps improve $\mathrm{HbA} 1 \mathrm{c}$, no research studies have analyzed the differences in $\mathrm{HbA} 1 \mathrm{c}$ levels and sport participation in children with T1D. Therefore, the purpose of this study was to examine the associations between PA and sport participation on $\mathrm{HbA1c}$ levels in children with T1D. The influence of sociodemographic characteristics and use of diabetes management tools (e.g., insulin pump) on $\mathrm{HbA1c}$ were also explored.

Identifying more direct benefits of increased PA on diabetes management and glucose control may aid diabetes care teams in developing individualized prescriptions to increase daily PA in a safe manner due to their understanding of acute and chronic physiological response for children managing T1D. The most prevalent and accessible measure in determining glucose control is the hemoglobin $\mathrm{A} 1 \mathrm{c}(\mathrm{HbA} 1 \mathrm{c})$ test which is an indicator of the average blood glucose levels over the past 3 months. Children managing T1D should strive for $\mathrm{HbA1c}$ levels less than $7 \%$ as an elevated $\mathrm{HbA} 1 \mathrm{c}$ level is known to increase the risk for diabetes related complications [17]. It is important for health professionals, parents, and even teachers to understand children's PA and sport participation behaviors and how they are associated with glucose control in children with T1D.

\section{Materials and Methods}

\subsection{Procedures}

This cross-sectional study was conducted at the Wendy Novak Diabetes Center, a nationally certified pediatric diabetes care and academic medical center located in the Southeastern United States. The study was approved by the University Institutional Review Board (IRB \#18.0713) and parental/guardian informed consent and child assent were obtained prior to study participation. Patients between the ages of 7 to 17 years old with T1D were invited to participate in this study while in the diabetes care clinic for their regularly scheduled clinic appointment. Interested participants were given an iPad to complete the informed consent/assent process and the PA and sport participation survey which took approximately $10 \mathrm{~min}$ to complete. The survey was housed within REDCap [18] on a secure server. Survey data were linked to the clinical database at the Wendy Novak Diabetes Center by the researchers utilizing the patients' medical record numbers to retrieve the measured $\mathrm{HbA} 1 \mathrm{c}$ values from that same day appointment for each participant. Once data were collected and merged, the full dataset was de-identified for analysis.

\subsection{Demographic Characteristics, Diabetes Monitoring, Treatment Plans and Outcomes}

Demographic characteristics utilized were participants' age, duration of T1D diagnosis, ethnicity, race, gender, insurance type, and body composition. Instead of using the more traditional body mass index (BMI) Z score, this study reports children's body composition using the tri-ponderal mass index (TMI) calculation of $\mathrm{kg} / \mathrm{m}^{3}$ as it has been shown to provide better reliability in determining the body composition of growing children $[19,20]$. Diabetes monitoring was assessed whether a participant used a continuous glucose monitor (CGM), an insulin pump, or relied solely on self-injections and monitoring. The dependent 
outcome variable $\mathrm{HbA} 1 \mathrm{c}$ level, a continuous variable ranging from 6.4 to $14.9 \%$, was obtained from that day's clinical lab measures.

\subsection{Physical Activity and Sport Participation}

Two survey items from the 2017 Youth Risk Behavior Surveillance System (YRBSS) questionnaire were used in this study [21]. PA participation was assessed by the following item: "During the past 7 days, on how many days were you physically active for a total of at least $60 \mathrm{~min}$ per day? (Add up all the time you spend in any kind of physical activity that increased your heart rate and made you breathe hard some of the time)" with response options ranging from 0-7 days. Sport participation was assessed by the following item: "During the past 12 months, on how many sports teams did you play? (Include any teams run by your school or community)" with response items ranging from 0 to 3 or more teams. Both YRBSS items have been shown to be valid and reliable in populations of children of similar ages [22].

\subsection{Data Analysis}

Survey data and clinical data were imported from REDCap into a spreadsheet for analysis using statistical software SPSS (IBM SPSS Statistics, Version 25.0. Armonk, NY, USA). All variables were tested for normality in which it was discovered that the $\mathrm{HbA} 1 \mathrm{c}$ measure did not follow a normal distribution. Therefore, HbA1c was log transformed prior to statistical analysis. PA and sport participation were analyzed individually by separating participants into groups according to number of days per week of PA and sport participation. This was done in an effort to further examine the differences between self-reported weekly PA, sport participation, and HbA1c. For the first analysis participants were grouped into tertiles according to number of days they reported to have accumulated 60 min or more of PA within the past week. Levels of PA were determined by splitting the data into three equal groups, which are as follows: Tertile 1: 0-2 days/week of $\geq 60 \mathrm{~min} / \mathrm{PA}$; Tertile 2: 3-4 days/week of $\geq 60 \mathrm{~min} / \mathrm{PA}$; Tertile 3: 5-7 days/week of $\geq 60 \mathrm{~min} / \mathrm{PA}$. To test the dependent variable $\mathrm{HbA} 1 \mathrm{c}$ a one-way ANOVA was used to determine significant differences between groups. Post hoc between-groups comparisons were carried out using Tukey's HSD to account for multiple testing. Due to the unequal distribution of sample sizes for race and ethnicity a Kruskall-Wallis test was used for differences in those groups. For sport participation, participants were separated into two groups based on whether or not they participated in an organized sport within the past year. Since this placed the sample into unevenly distributed groups, the non-parametric independent-samples Mann-Whitney $\mathrm{U}$ test was used for analysis.

In the secondary analyses, multiple linear regression models with $\mathrm{HbA} 1 \mathrm{c}$ as the dependent variable were employed to examine the association between $\mathrm{HbA} 1 \mathrm{c}$ and PA. To examine the relationships between PA and other known covariates on $\mathrm{HbA1c}$ independent of one another two multiple regression analyses were run with PA as the independent variable and $\mathrm{HbA} 1 \mathrm{c}$ as the dependent variable in all models. The first model adjusted for potential confounding factors that were identified as being significantly associated to $\mathrm{HbA} 1 \mathrm{c}$ through a Pearson's correlation analysis. A second regression model also controlled for the independent variables of the other model while including additional sociodemographic and diabetes management variables. To allow for direct comparison across covariates, results of the linear regression analysis also present the standardized beta coefficient. A $p$-value of $<0.05$ was considered statistically significant for all statistical analyses.

\section{Results}

\subsection{Characteristics of the Participants}

A total of 153 participants submitted a completed survey. One outlier was identified and removed from the dataset leaving a total of 152 participants in the final analysis. Table 1 shows the sample characteristics and variables of all participants, as well as the separation into groups according to daily PA. Participants consisted of 71 females (46.71\%) 
and 81 males (53.29\%), were $13 \pm 3$ years of age with an average $\mathrm{HbA1c}$ level of $8.75 \pm 1.81$. They were, on average, physically active for $60 \mathrm{~min}$ or more $3.49 \pm 1.95$ days per week. Only $7.9 \%(n=12)$ met the minimal recommendation of daily PA although almost two-thirds played sports $(n=98,64.1 \%)$.

Table 1. Demographic characteristics and diabetes treatment measures for all participants and ANOVA results separated by physical activity group.

\begin{tabular}{|c|c|c|c|c|c|c|}
\hline Variable & Category & All & Inactive & Active & Most Active & $p$-Value \\
\hline Number & & 152 & $51(33.55 \%)$ & $50(32.9 \%)$ & $51(33.55 \%)$ & \\
\hline \multirow{4}{*}{$\begin{array}{l}\text { Age (avg. yrs) } \\
\text { Gender }\end{array}$} & & $13 \pm 3$ & $14 \pm 3$ & $13 \pm 3$ & $13 \pm 3$ & 0.12 \\
\hline & & & & & & 0.25 \\
\hline & Female & $71(46.71 \%)$ & $26(50.98 \%)$ & $26(52 \%)$ & $19(37.25 \%)$ & \\
\hline & Male & $81(53.29 \%)$ & $25(49.02 \%)$ & $24(48 \%)$ & $32(62.75 \%)$ & \\
\hline \multirow[t]{4}{*}{ Race } & & & & & & 0.05 \\
\hline & Black & $13(8.55 \%)$ & $8(15.69 \%)$ & $1(2 \%)$ & $4(7.84 \%)$ & \\
\hline & White & $134(88.16 \%)$ & $41(80.39 \%)$ & $46(92 \%)$ & $47(92.16 \%)$ & \\
\hline & Other & $5(3.29 \%)$ & $2(3.92 \%)$ & $3(6 \%)$ & 0 & \\
\hline \multirow[t]{3}{*}{ Ethnicity } & & & & & & 0.07 \\
\hline & Hispanic or Latino & $5(3.29 \%)$ & $4(7.84 \%)$ & $1(2 \%)$ & 0 & \\
\hline & $\begin{array}{l}\text { Not Hispanic } \\
\text { or Latino }\end{array}$ & $147(96.71 \%)$ & $47(92.16 \%)$ & $49(98 \%)$ & $51(100 \%)$ & \\
\hline \multirow[t]{3}{*}{ CGM Use } & & & & & & 0.73 \\
\hline & Yes & $77(50.66 \%)$ & $24(47.06 \%)$ & $25(50 \%)$ & $28(54.9 \%)$ & \\
\hline & No & $75(49.34 \%)$ & $27(52.94 \%)$ & $25(50 \%)$ & $23(45.1 \%)$ & \\
\hline \multirow[t]{3}{*}{ Insulin Pump } & & & & & & 0.85 \\
\hline & Yes & $115(75.66 \%)$ & $40(78.43 \%)$ & $37(74 \%)$ & $38(74.51 \%)$ & \\
\hline & No & 37 (24.34\%) & $11(21.57 \%)$ & $13(26 \%)$ & $13(25.49 \%)$ & \\
\hline $\begin{array}{l}\text { Years diagnosed } \\
\text { with T1D }\end{array}$ & & $4.78 \pm 3.91$ & $5.67 \pm 4.06$ & $3.84 \pm 3.59$ & $4.82 \pm 3.91$ & 0.06 \\
\hline Height (m) & & $156.54 \pm 15.60$ & $158.43 \pm 14.83$ & $154.32 \pm 15.28$ & $157.12 \pm 16.67$ & 0.40 \\
\hline Weight (kg) & & $54.36 \pm 16.97$ & $57.30 \pm 18.92$ & $53.32 \pm 14.99$ & $52.45 \pm 16.67$ & 0.31 \\
\hline TMI $\left(\mathrm{kg} / \mathrm{m}^{3}\right)$ & & $13.91 \pm 2.85$ & $14.09 \pm 3.14$ & $14.34 \pm 2.75$ & $13.31 \pm 2.59$ & 0.16 \\
\hline $\mathrm{HbA1c}$ & & $8.75 \pm 1.81$ & $9.42 \pm 2.18$ & $8.37 \pm 1.70$ & $8.46 \pm 1.29$ & 0.007 \\
\hline \multirow[t]{3}{*}{ Sport Participation } & & & & & & $<0.001$ \\
\hline & Yes & $97(63.82 \%)$ & $22(43.14 \%)$ & $35(70 \%)$ & $40(78.43 \%)$ & \\
\hline & No & $55(36.18 \%)$ & $2956.86 \%)$ & $15(30 \%)$ & $11(21.57 \%)$ & \\
\hline & & $3.49 \pm 1.95$ & $1.29 \pm 0.83$ & $3.48 \pm 0.50$ & $5.69 \pm 0.84$ & $<0.001$ \\
\hline \multirow{3}{*}{ Insurance Type } & Private Company & $87(57.24 \%)$ & $29(56.86 \%)$ & $30(60 \%)$ & $28(54.9 \%)$ & 0.88 \\
\hline & Medicare/Medicaid & $122(80.26 \%)$ & $46(90.2 \%)$ & $39(78 \%)$ & $37(72.55 \%)$ & 0.07 \\
\hline & None & $2(1.32 \%)$ & $1(1.96 \%)$ & 0 & $1(1.96 \%)$ & 0.61 \\
\hline
\end{tabular}

Abbreviations: HbA1C = glycated hemoglobin; T1D = Type 1 Diabetes; PA = physical activity; CGM = continuous glucose monitor; TMI $=$ Tri-ponderal mass index.

\subsection{Associations between Frequency of Physical Activity, Sport Participation and Diabetes Health Measures}

A one-way ANOVA showed statistically significant differences between PA groups indicating lower values of $\mathrm{HbA} 1 \mathrm{c}$ as daily PA increased $(p<0.01)$ (Table 1$)$. In a Tukey post-hoc analysis of the sub-groups it was further shown that the significant differences were observed between the Inactive and Active groups in terms of $\operatorname{HbA1c}(p=0.01)$, as well as the Inactive and Most Active groups $(p=0.03)$ (Figure 1). Comparisons between PA groups Active and Most Active did not have a significant difference in $\mathrm{HbA1c}(p=0.88)$. To examine the association between sport participation and $\mathrm{HbA} 1 \mathrm{c}$, an independent-samples Mann-Whitney $U$ test was used and revealed no significant difference between sport participation and $\mathrm{HbA} 1 \mathrm{c}$ levels $(p=0.27)$. 


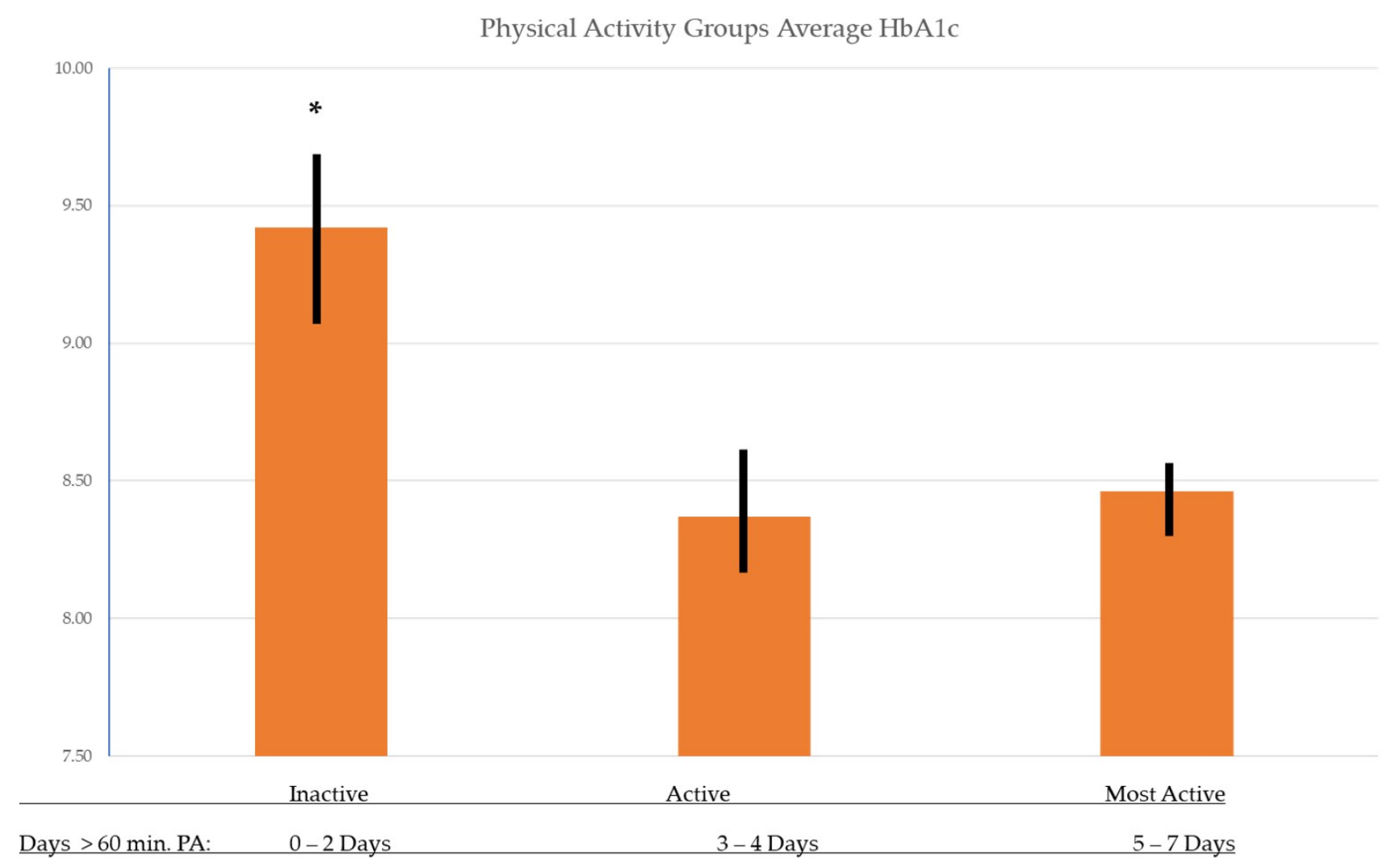

* Significant difference between Group 1 and $2(p<0.05)$ and Group 1 and $3(\mathrm{p}<0.05)$, but not Group 2 and $3(\mathrm{p}=0.88)$.

Figure 1. Differences in HbA1c Across Physical Activity Groups.

Pearson's correlation revealed significant relationships were also observed between $\mathrm{HbA1c}$ and age $(r=0.19, p=0.01)$, race $(r=-0.18, p=0.03)$, CGM use $(r=-0.22, p=0.006)$, and duration of T1D diagnosis $(r=0.23, p=0.004)$. In order to analyze factors influencing $\mathrm{HbA1c}$, multiple regression analyses were performed in the whole population with total days of PA as the independent variable instead of the respective PA groups. Results from the regression analyses indicated that the more days a child engages in $60 \mathrm{~min}$ or more of PA the lower their HbA1c compared to less active children from this sample (Table 2). The first model adjusted for variables that had a significant correlation with $\mathrm{HbA1c}$ (i.e., disease duration, CGM use, age, and race), in which it was found that in addition to daily PA, other significant predictors of $\mathrm{HbA1c}$ included race, CGM use, and disease duration, but not age. After adjustment for all sociodemographic variables (Model 2), the association with daily PA was still statistically significant with a $\beta$-coefficient that changed to $-0.18(95 \% \mathrm{CI}$ : -0.32 to -0.02 ) indicating an even stronger relationship when taking into consideration other impacts on health like insurance and common medical devices designed to help improve diabetes management as indicated in these models (i.e., CGM use and duration of diagnosis).

Table 2. Adjusted associations of sociodemographic, anthropometric, and physical activity with glycated hemoglobin $(n=152)$.

\begin{tabular}{|c|c|c|c|c|c|c|c|c|}
\hline \multicolumn{9}{|c|}{ Independent Variable HbA1c } \\
\hline & & Model 1 a & & & & Model $2^{b}$ & & \\
\hline Variable & $\beta$ (SE) & Standardized Beta & $t$ & $p$-Value & $\beta$ (SE) & Standardized Beta & $t$ & $p$-Value \\
\hline Intercept & $11.14(1.35)$ & & 8.23 & $<0.01$ & $13.2(2.32)$ & & 5.69 & $<0.001$ \\
\hline $\begin{array}{l}\text { Days of PA } \\
\text { per week }\end{array}$ & $-0.15(0.07)$ & -0.16 & -2.08 & 0.03 & $-0.17(0.07)$ & -0.18 & -2.26 & 0.02 \\
\hline
\end{tabular}


Table 2. Cont.

\begin{tabular}{|c|c|c|c|c|c|c|c|c|}
\hline \multicolumn{9}{|c|}{ Independent Variable HbA1c } \\
\hline \multirow[b]{2}{*}{ Variable } & \multicolumn{4}{|c|}{ Model 1 a } & \multicolumn{4}{|c|}{ Model $2^{b}$} \\
\hline & $\beta$ (SE) & Standardized Beta & $t$ & $p$-Value & $\beta$ (SE) & Standardized Beta & $t$ & $p$-Value \\
\hline Age & $0.06(0.05)$ & 0.09 & 1.06 & 0.29 & $0.04(0.05)$ & 0.06 & 0.72 & 0.47 \\
\hline Race & $-0.66(0.29)$ & -0.17 & -2.25 & 0.03 & $-0.73(0.34)$ & -0.19 & -2.12 & 0.04 \\
\hline CGM use & $-0.66(0.28)$ & -0.18 & -2.40 & 0.02 & $-0.74(0.28)$ & -0.21 & -2.69 & 0.01 \\
\hline $\begin{array}{l}\text { Diagnosis } \\
\text { Duration }\end{array}$ & $0.08(0.04)$ & 0.17 & 2.15 & 0.03 & $0.09(0.04)$ & 0.19 & 2.30 & 0.02 \\
\hline Gender & & & & & $-0.50(0.29)$ & -0.14 & -1.73 & 0.09 \\
\hline Ethnicity & & & & & $-0.27(0.92)$ & -0.03 & -0.30 & 0.77 \\
\hline $\begin{array}{c}\text { TMI } \\
\left(\mathrm{kg} / \mathrm{mt}^{2}\right)\end{array}$ & & & & & $-0.02(0.05)$ & -0.03 & -0.30 & 0.76 \\
\hline $\begin{array}{l}\text { Insulin } \\
\text { Pump use }\end{array}$ & & & & & $0.04(0.32)$ & 0.01 & 0.13 & 0.89 \\
\hline $\begin{array}{c}\text { Insurance } \\
\text { Type }\end{array}$ & & & & & $-0.70(0.29)$ & -0.15 & -1.94 & 0.06 \\
\hline
\end{tabular}

Abbreviations: $\mathrm{Hb}$ A1C = glycated hemoglobin; PA = physical activity; CGM = continuous glucose monitor; TMI = Tri-ponderal mass index. ${ }^{a}$ Model 1 = adjusted for physical activity, age, race, diagnosis duration, and CGM use. ${ }^{\mathrm{b}}$ Model 2 = adjusted for physical activity, age, race, CGM use, diagnosis duration in years, gender, ethnicity, TMI, insulin pump use, and insurance type.

\section{Discussion}

This study sought to determine the extent to which PA and sport participation are associated with $\mathrm{HbA1c}$ levels in children with T1D as well as explore the strength of relationships among demographics, diabetes treatment, $\mathrm{HbA1c}$, $\mathrm{PA}$, and sport participation characteristics. The results of this study indicated that children's HbA1c improved with PA, but that sport participation alone may not be enough activity to have any positive impact on $\mathrm{HbA} 1 \mathrm{c}$ according to this sample. When separated by days of PA, results showed that children who accumulated $60 \mathrm{~min}$ of PA at least 3 days or more out of the week presented with lower $\mathrm{HbA} 1 \mathrm{c}$ levels when compared to children achieving 60 min of PA only two days out of the week or less. Compared to the Inactive PA group this significant finding was also observed in children who only accumulated 3 to 4 days of PA, which is less than the current recommended amount of $60 \mathrm{~min}$ or more of moderate to vigorous physical activity every day of the week (Figure 1). This trend would suggest potential benefit for those children who struggle to meet the current guidelines every single day of the week.

Although almost $2 / 3$ of the children reported playing 1 or more sports in the previous year, they were only physically active for at least $1 \mathrm{~h}$ or more on average 3.49 days per week. Of important practical and clinical consideration is that less than $8 \%$ of the children in this sample met the recommended duration of one hour and frequency of 7 days per week of PA. Considering that the American Diabetes Association recommends PA as a key behavior in managing T1D effectively, the children in this study were quite sedentary. Results from 2017 YRBSS data indicated that nationally $26.1 \%$ (17.5\% girls and 35.3\% boys) and state-wide $22.0 \%$ ( $12.8 \%$ girls and $31.0 \%$ boys) were physically active [21]. The sample of children in this study fell far from meeting these PA minimal guidelines.

Sport participation has long been touted as a way for children to increase duration in PA and improve overall health and T1D management [23]. Specifically, previous research has shown PA affected $\mathrm{HbA1c}$ levels: the more days active, the lower the child's $\mathrm{HbA} 1 \mathrm{c}$ level. Beraki and colleagues [15] found that less active children had an average $\mathrm{HbA} 1 \mathrm{c}$ level of $8.8 \pm 1.5$, while more active children had an average $\mathrm{HbA1c}$ level of 7.7, $\mathrm{SD} \pm 1.0$. Thus, sport participation, at first glance, appears to be a promising avenue for children with T1D to consider when trying to increase their PA levels. Interestingly $64.4 \%$ of the children in this sample played on at least 1 sports team in the past year, more than the national results $54.3 \%$ (49.3\% girls and $59.7 \%$ boys) and statewide results of $48.3 \%$ (46.5\% girls and $50.5 \%$ boys). The findings from this study suggest that daily PA had more of an impact on 
reducing $\mathrm{HbA} 1 \mathrm{c}$ levels for children with T1D than sport participation alone. These findings would also suggest that children participating in sports is not enough activity by itself to meet current recommended guidelines.

A systematic review of 23 studies with meta-analysis indicated that PA is important for diabetes management but there is a lack of studies promoting sustained PA [24]. There remains a lack of knowledge of how to safely support and promote PA in people with T1D. Results from research on self-management of T1D in the school setting has identified that while some schools have procedures that support the participation of youth with T1D in sports, other schools require that the parents be present in order for their child to participate. A lack of knowledge of T1D among school staff and coaches can be a barrier to PA among youth with T1D [25,26].

Further, results from the exploration into the demographic and PA relationship indicate that there was a negative relationship between physical activity and age, meaning that older children were less active which is concurrent in the research. Recent YRBSS findings indicate that only $35 \%$ of high school boys and $18 \%$ of high school girls engaged in $60 \mathrm{~min}$ of daily PA. Younger children are typically more active than older children. For example, children 6-11 years engaged in $88 \mathrm{~min}$ of daily physical activity compared to adolescents aged $12-15$ years (33 $\mathrm{min})$, and $16-19$ years (26 $\mathrm{min}$ ) [27].

Children's participation in physical activity may be limited due to lack of access to medically supervised PA opportunities for children managing T1D, and further complicated by logistical or financial reasons, especially among minority or low socioeconomically disadvantaged communities [28]. The participants' demographic characteristics of race, ethnicity, and gender were an approximate reflection of the population in the state and surrounding geographical areas. It is interesting to note that most of the children were enrolled in Medicare/Medicaid which can be indicative of lower socioeconomic status, especially considering that on average, a family with a child with T1D pays extra in medical care coverage, insurance, and expenses per year than a family without T1D. A little over one-half of the sample had additional private insurance and about one-half of the sample used a CGM as well. What is most concerning with the results of the current study is the observation of other significant predictors of $\mathrm{HbA1c}$ including race and CGM use which would provide additional evidence in support of racial disparities that exist in healthcare. Even with a smaller sample size, it was found that participants who identified as Black or Other had a significantly higher HbA1c compared to Caucasian participants (10.46 vs. 8.52; $p<0.001)$ after running a separate non-parametric independent samples test.

Although the results from this study did not detect statistical significance in $\mathrm{HbA1c}$ outcomes and sport participation, further research is encouraged from the clinical and exercise communities. With strong evidence indicating the importance of daily PA and sport participation on health, proper growth, and motor function for children of all ages recent initiatives have been put in place to help children and youth increase daily PA through sport participation [29]. Thus, hypothetically sport participation can be a way for T1D patients to improve $\mathrm{HbA1c}$, yet more research studies are required to specifically analyze the differences in $\mathrm{HbA} 1 \mathrm{c}$ levels and sport participation in children with T1D. For children with T1D, the diligence required to adequately maintain blood glucose levels, while still participating in sports, can be challenging for both the children and their families. For example, children having to stop in the middle of a sport game to treat hypoglycemia and then wait for their blood sugar to return to a safe level before participating again, can be discouraging and frustrating [30].

For children with T1D to safely and confidently participate in PA such as recess, physical education class, or sports, a comprehensive team approach among the child, parents, coaches, and medical providers must ensue. National initiatives, grounded in research, recommend that all children, including those with health conditions, have equal opportunities to participate in sports [21,27-29]. Physicians and medical care teams can prescribe PA and sport participation when designing treatment plans and to refer qualified health and fitness professionals. 
This study is not without limitations. The analysis was underpowered and a larger sample size may have helped reach significant findings in areas related to sport participation. The broad range in ages possibly affected the results since some of the participants had either started puberty, or were currently experiencing changes in hormone production while in the middle of puberty. Further, it seems prudent to revisit the research hypothesis with additional participants in the future. Additionally, future research should further investigate potential covariates of the relationship between sport participation, PA, and $\mathrm{HbA} 1 \mathrm{c}$ levels that were identified in the present study and other variables not collected here. It would also be necessary to make sure that any measurements related to diabetes management (i.e., $\mathrm{HbA1c}$ ) are collected within a similar time-frame as sporting seasons, which this study did not do. Some participants may not have been actively participating in a sport within the past 6 months or more prior to the $\mathrm{HbA1c}$ reported in this study and we acknowledge this had an impact on our findings.

\section{Conclusions}

$\mathrm{HbA1c}$ levels showed a trending decrease with each day a child engaged in PA, only the number of days a child was active per week was a significant predictor of better $\mathrm{HbA} 1 \mathrm{c}$ levels. Clinical applications of this study center around the idea that healthcare providers should be educated about the positive influence that PA and sport participation may have on $\mathrm{HbA1c}$ levels in their patients living with T1D.

To develop a truly collaborative clinical and translational research effort in which research and clinical practice work in tandem to help inform each other, it is important for health professionals and researchers to understand children's PA and sport participation characteristics and their impact on the glucose response to ensure safety. Understanding patients' demographic characteristics, physical activity, and sport participation behaviors, and diabetes monitoring, treatment plans, and outcomes may aid sports medicine programs in developing sport-specific programs, identifying specific sports teams in which to partner, and developing sport- and PA-specific recommendations. Since the number of days active per week was a significant predictor of better $\mathrm{HbA1c}$, it behooves diabetes care teams to encourage PA in addition to sport participation alone. Further investigation should address socioecological barriers to PA and sport participation.

Author Contributions: Formal analysis, J.R.J., L.J.D. and K.M.K.; Funding acquisition, K.A.W.; Investigation, K.M.K.; Methodology, K.M.K., L.J.D. and A.E.K.; Project administration, T.M. and A.E.K.; Supervision, K.M.K., J.R.J. and T.M.; Writing-original draft, K.M.K., J.R.J. and A.E.K.; Writingreview \& editing, K.M.K., J.R.J., L.J.D., T.M., S.W., K.R.H. and K.A.W. All authors have read and agreed to the published version of the manuscript.

Funding: This study was made possible by generous support from the Christensen Family, the Children's Hospital Foundation, and the University of Louisville Foundation.

Institutional Review Board Statement: This study was approved by the University's Institutional Review Board on 11/05/2018 (Approval \# 18.0713).

Informed Consent Statement: Informed consent was obtained from all subjects involved in the study.

Data Availability Statement: The data presented in this study are available on request from the corresponding author.

Conflicts of Interest: The authors declare no conflict of interest. The funders had no role in the design of the study; in the collection, analyses, or interpretation of data; in the writing of the manuscript, or in the decision to publish the results.

\section{References}

1. American College of Sports Medicine. ACSM's Guidelines for Exercise Testing and Prescription, 10th ed.; Riebe, D., Ehrman, J., Liguori, G., Magal, M., Eds.; Wolters Kluwer: Philadelphia, PA, USA, 2018.

2. American College of Sports Medicine. Exercise is Medicine 2018. Available online: http:/ /www.exerciseismedicine.org/ (accessed on 2 August 2020). 
3. MacMillan, F.; Kirk, A.; Mutrie, N.; Matthews, L.; Robertson, K.; Saunders, D.H. A systematic review of physical activity and sedentary behavior intervention studies in youth with type 1 diabetes: Study characteristics, intervention design, and efficacy. Pediatric Diabetes 2014, 15, 175-189. [CrossRef] [PubMed]

4. Colberg, S.R.; Sigal, R.J.; Yardley, J.E.; Riddell, M.C.; Dunstan, D.W.; Dempsey, P.C.; Horton, E.S.; Castorino, L.; Tate, D.F. Physical Activity/Exercise and Diabetes: A Position Statement of the American Diabetes Association. Diabetes Care 2016, 39, $2065-2079$. [CrossRef] [PubMed]

5. Colberg, S.R. The Athlete's Guide to Diabetes; Human Kinetics: Champaign, IL, USA, 2020.

6. United States Department of Health and Sport Sciences (USDHHS). Physical Activity Guidelines for Americans, 2nd ed.; Services USDHHS: Washington, DC, USA, 2018.

7. Jaggers, J.R.; Casto Hynes, K.; Wintergerst, K.A. Exercise and Sport Participation for Individuals with Type 1 Diabetes. ACSM's Health Fit. J. 2016, 20, 40-44. [CrossRef]

8. Jaggers, J.R.; King, K.M.; Watson, S.E.; Wintergerst, K.A. Predicting nocturnal hypoglycemia with measures of physical activity intensity in adolescent athletes with type 1 diabetes. Diabetes Technolol. Ther. 2019, 21, 406-408. [CrossRef] [PubMed]

9. Riddell, M.C.; Gallen, I.W.; Smart, C.E.; Taplin, C.E.; Adolfsson, P.; Lumb, A.N.; Kowalski, A.; Rabasa-Lhoret, R.; McCrimmon, R.J.; Hume, C.; et al. Exercise management in type 1 diabetes: A consensus statement. Lancet Diabetes Endocrinol. 2017, 5, 377-390. [CrossRef]

10. Åman, J.; Skinner, T.; de Beaufort, C.; Swift, P.; Aanstoot, H.; Cameron, F. Associations between physical activity, sedentary behavior, and glycemic control in a large cohort of adolescents with type 1 diabetes: The Hvidoere Study Group on Childhood Diabetes. Pediatric Diabetes 2009, 10, 234-239. [CrossRef]

11. Aljawarneh, Y.M.; Wardell, D.W.; Wood, G.L.; Rozmus, C.L. A Systematic Review of Physical Activity and Exercise on Physiological and Biochemical Outcomes in Children and Adolescents With Type 1 Diabetes. J. Nurs. Scholarsh. 2019, 51, 337-345. [CrossRef]

12. Elmesmari, R.; Reilly, J.J.; Martin, A.; Paton, J.Y. Accelerometer measured levels of moderate-to-vigorous intensity physical activity and sedentary time in children and adolescents with chronic disease: A systematic review and meta-analysis. PLoS ONE 2017, 12, 1-20. [CrossRef] [PubMed]

13. Galler, A.; Lindau, M.; Ernert, A.; Thalemann, R.; Raile, K. Associations between media consumption habits, physical activity, socioeconomic status, and glycemic control in children, adolescents, and young adults with type 1 diabetes. Diabetes Care 2011, 34, 2356-2359. [CrossRef]

14. Mandic, S.; Bengoechea, E.G.; Stevens, E.; de la Barra, S.L.; Skidmore, P. Getting kids active by participating in sport and doing it more often: Focusing on what matters. Int. J. Behav. Nutr. Phys. Act. 2012, 9, 86. [CrossRef] [PubMed]

15. Beraki, A.; Magnuson, A.; Särnblad, S.; Aman, J.; Samuelsson, U. Increase in physical activity is associated with lower HbA1c levels in children and adolescents with type 1 diabetes: Results from a cross-sectional study based on the Swedish pediatric diabetes quality registry (SWEDIABKIDS). Diabetes Res. Clin. Pract. 2014, 105, 119-125. [CrossRef] [PubMed]

16. Valerio, G.; Spagnuolo, M.I.; Lombardi, F.; Spadaro, R.; Siano, M.; Franzese, A. Physical activity and sports participation in children and adolescents with type 1 diabetes mellitus. Nutr. Metab. Cardiovasc. Dis. 2007, 17, 376-382. [CrossRef]

17. American Diabetes Association. 13. Children and Adolescents: Standards of Medical Care in Diabetes-2020. Diabetes Care 2020, 43 (Suppl. 1), S163-S182.

18. Harris, P.A.; Taylor, R.; Thielke, R.; Payne, J.; Gonzalez, N.; Conde, J.G. Research electronic data capture (REDCap)—A metadatadriven methodology and workflow process for providing translational research informatics support. J. Biomed. Inform. 2009, 42, 377-381. [CrossRef] [PubMed]

19. Peterson, C.M.; Su, H.; Thomas, D.M.; Heo, M.; Golnabi, A.H.; Pietrobelli, A.; Heymsfield, S.B. Tri-Ponderal Mass Index vs Body Mass Index in Estimating Body Fat During Adolescence. JAMA Pediatrics 2017, 171, 629-636. [CrossRef]

20. Park, H.K.; Shim, Y.S. Distribution of Tri-Ponderal Mass Index and its Relation to Body Mass Index in Children and Adolescents Aged 10 to 20 Years. J. Clin. Endocrinol. Metab. 2020, 105, e826-e834. [CrossRef] [PubMed]

21. Kann, L.; McManus, T.; Harris, W.A.; Shanklin, S.L.; Flint, K.H.; Queen, B.; Lowry, R.; Chyen, D.; Whittle, L.; Thornton, J.; et al. Youth Risk Behavior Surveillance-United States, 2017. MMWR Surveill. Summ. 2018, 67, 1-114. [CrossRef]

22. Booth, M.L.; Okely, A.D.; Chey, T.; Bauman, A. The reliability and validity of the adolescent physical activity recall questionnaire. /Fiabilite du questionnaire de rappel sur 1' activite physique des adolescents. Med. Sci. Sports Exerc. 2002, 34, 1986-1995. [CrossRef]

23. Colberg, S. Exercise and Diabetes: A Clinician's Guide to Prescribing Physical Activity, 1st ed.; American Diabetes Association: Arlington, VA, USA, 2013; pp. 28-29.

24. Quirk, H.; Blake, H.; Tennyson, R.; Randell, T.L.; Glazebrook, C. Physical activity interventions in children and young people with Type 1 diabetes mellitus: A systematic review with meta-analysis. Diabet. Med. 2014, 31, 1163-1173. [CrossRef]

25. Edwards, D.; Noyes, J.; Lowes, L.; Haf Spencer, L.; Gregory, J.W. An ongoing struggle: A mixed-method systematic review of interventions, barriers and facilitators to achieving optimal self-care by children and young people with type 1 diabetes in educational settings. BMC Pediatr. 2014, 14, 228. [CrossRef]

26. Ryninks, K.; Sutton, E.; Thomas, E.; Jago, R.; Shield, J.P.; Burren, C.P. Attitudes to Exercise and Diabetes in Young People with Type 1 Diabetes Mellitus: A Qualitative Analysis. PLoS ONE 2015, 10, e0137562. [CrossRef] [PubMed] 
27. Belcher, B.R.; Berrigan, D.; Dodd, K.W.; Emken, B.A.; Chou, C.P.; Spruijt-Metz, D. Physical activity in US youth: Effect of race/ethnicity, age, gender, and weight status. Med. Sci. Sports Exerc. 2010, 42, 2211-2221. [CrossRef]

28. Jones, S.A.; Moore, L.V.; Moore, K.; Zagorski, M.; Brines, S.J.; Roux, A.V.D.; Evenson, K.R. Disparities in physical activity resource availability in six US regions. Prev. Med. 2015, 78, 17-22. [CrossRef] [PubMed]

29. Katzmarzyk, P.T.; Denstel, K.D.; Beals, K.; Carlson, J.; Crouter, S.E.; McKenzie, T.L.; Pate, R.R.; Sisson, S.B.; Staiano, A.E.; Stanish, H.; et al. Results from the United States 2018 Report Card on Physical Activity for Children and Youth. J. Phys. Act. Health 2018, 15, S422-S424. [CrossRef]

30. Kahkoska, A.R.; Watts, M.E.; Driscoll, K.A.; Bishop, F.K.; Mihas, P.; Thomas, J.; Law, J.R.; Jain, N.; Mayer-Davis, E.J. Understanding antagonism and synergism: A qualitative assessment of weight management in youth with Type 1 diabetes mellitus. Obes. Med. 2018, 9, 21-31. [CrossRef] [PubMed] 